\title{
Conception rate hasil inseminasi buatan menggunakan semen sexing beku pada Sapi Persilangan Ongole
}

\section{Conception rate of artificial inseminationusing semen sexing on Ongole Crossbred Cow}

\author{
Aulia Puspita Anugra Yekti *, Titah Ulya Kurniaesa, Nurul Isnaini, Kuswati, Trinil Susilawati
}

Fakultas Peternakan Universitas Brawijaya, Jl. Veteran Malang 65145 Jawa Timur

Submitted: 28 September 2018, Accepted: 04 Desember 2018

\begin{abstract}
ABSTRAK: Inseminasi Buatan (IB) merupakan teknik yang digunakan secara luas oleh peternak untuk meningkatkan mutu genetik dan kualitas ternak. Metode ini dapat ditingkatkan nilainya dengan menggunakan semen sexing yang dapat mengatur dan menghasilkan jenis kelamin anak sesuai dengan harapan. Tujuan penelitian ini adalah untuk mengetahui keberhasilan IB dengan menggunakan semen sexing beku pada sapi Persilangan Ongole di Kabupaten Malang. Materi yang digunakan adalah adalah 98 ekor sapi Persilangan Ongole yang terdapat di peternakan rakyat Kabupaten Malang dengan mengambil sampel di Kecamatan Pakis, Tumpang, Jabung dan Singosari. Metode yang digunakan adalah percobaan lapang dengan dua perlakuan yaitu 49 ekor induk sapi dengan IB menggunakan semen sexing (P1) dan 49 ekor induk sapi lainnya dengan IB menggunakan semen non sexing (P0).Variabel penelitian ini adalah nilai Non return Rate (NRR) selama 3 siklus birahi setelah IB dan nilai CR berdasarkan pengamatan kebuntingan usia 8 bulan kebuntingan ternak. Data dianalisa secara deskriptif dan dilanjutkan dengan uji proporsi satu pihak. Hasil pengamatan menunjukkan nilai CR pada P1 menghasilkan angka yang lebih rendah yaitu sebesar 55,10\% ternak bunting dibandingkan pada P0yaitu diperoleh $65,31 \%$ ternak bunting. Sedangkan, nilai NRR yang didapatkan pada perlakuan IB menggunakan semen sexing dari $87,76 \%$ menjadi $73,47 \%$ dan $67,35 \%$, sedangkan pada IB menggunakan semen non sexing dari 95,92\% menjadi $83,67 \%$ dan $75,51 \%$. Dapat disimpulkan bahwa nilai CR dan NRR pada sapi yang di IB dengan semen sexing lebih rendah dibandingkan dengan yang di IB menggunakan semen non sexing, namun semen sexing masih tetap dapat diaplikasikan untuk tujuan tertentu seperti mendapatkan anak sesuai dengan harapan.
\end{abstract}

Kata kunci : Inseminasi Buatan; semen sexing; Non Return Rate; Conception Rate.

ABSTRACT: Artificial Insemination (AI) is a technique that is widely used by farmers to improve the genetic quality of livestock. This method can be increased in value by using sexing semen that can regulate and produce the sex of the offspring as expected. The purpose of this study was to determine the success of AI by using frozen sexing semen on Ongole Crossbred cows in Malang Regency. The materials used were 98 Ongole crossbred cows in traditional farm of Malang Regency especially in Pakis, Tumpang, Jabung and Singosari Districts. The method used was a field experiment with two treatments: 49 cows were inseminated by using frozen sexing semen (P1) and 49 cows were inseminated by using non sexing semen (P0). The variables observed were the Non-Return Rate (NRR) value observedin 3 estrous cycle after AI and CR value based on pregnancy observation at 8 months of pregnancy. Data were analyzed descriptively and continued with a one-proportion z-test. The datashowed that the CR value on $\mathrm{P} 1$; P0 were $55.10 \%$ and $65,31 \%$ respectively.furthemore, the NRR value on $\mathrm{P} 1$ from $\mathrm{NRR}_{1}$ to $\mathrm{NRR}_{3}$ were $87,76 \%, 73,47 \%$ and $67,35 \%$, while on $\mathrm{P} 095,92 \%, 83,67 \%$ and $75,51 \%$ respectively.It can be conclude thatCR and NRR value of sexing semenwas lower than non sexing semen, however sexing semen can be applied for certain purposes such as producing offspring as expected

Keywords : Artificial insemination, sexing semen, non return rate, conception rate

"Corresponding Author: auliapay@ub.ac.id

DOI: 10.21776/ub.jiip.2018.028.03.07 


\section{PENDAHULUAN}

Program IB dapat ditingkatkan nilainya dengan menghasilkan bibit unggul yang memiliki jenis kelamin sesuai tujuan pemeliharaan (Susilawati, 2014). Teknologi yang dibutuhkan untuk pengaturan jenis kelamin anak tersebut dengan pengaplikasian semen sexing. Tujuan Inseminasi $\mathrm{Bu}-$ atan menggunakan semen sexing adalah agar mendapatkan anak sesuai harapan. Sexing adalah pemisahan spermatozoa $\mathrm{X}$ dan Y. Sperma X akan menghasilkan anak betina sedangkan sperma $\mathrm{Y}$ akan menghasilkan anak jantan (Prakash et al., 2014 ; Boro et al., 2016). Susilawati (2014) menyebutkan bahwa sexing menggunakan metode sentrifugasi gradien densitas percoll mampu memisahkan dengan ketepatan lebih dari $80 \%$ berdasarkan pada identifikasi pengukuran kepala spermatozoa. Oleh karena itu BBIB Singosari telah memproduksi semen sexing dengan metode sentrifugrasi gradien densitas percoll, Kusumawati et al (2017) menunjukkan bahwa sexing menggunakan sentrifugasi gradien percoll mempunyai motilitas setelah sexing pada populasi sperma Y sebesar 53,79 \pm 7,93\%.

Sapi dengan jenis kelamin jantan mempunyai nilai jual yang sangat tinggi dibandingkan dengan betina, sehingga minat masyarakat untuk mendapatkan anak dengan jenis kelamin jantan juga meningkat. Dengan adanya penelitian ini maka dapat meningkatkan peluang untuk menghasilkan anak dengan jenis kelamin jantan. Penelitian ini bertujuan untuk mengetahui keberhasilan IB melalui metode Non Return Rate (NRR) dan Conception Rate (CR) pada Sapi Persilangan Ongole menggunakan semen sexing.

\section{MATERI DAN METODE Lokasi dan waktu penelitian}

Penelitian ini dilaksanakan di peternakan rakyat wilayah Kabupaten Malang dengan mengambil sampel di Kecamatan Pakis, Tumpang, Jabung dan Singosari selama 10 bulan yang dimulai dari tanggal September 2017 -Juni 2018.

\section{Materi}

Materi yang digunakan dalam penelitian ini adalah 98 ekor sapi betina PO. Sampel dipilih secara purposive samplingpada sapi betina dengan kriteria sapi betina dara (sapi berumur 1-2 tahun dan belum pernah partus) atau sapi betina indukan (sapi berumur $\geq 2,5$ tahun atau sudah beranak 1 kali), sehat, bebas dari penyakit reproduksi dan minimal dalam kondisi berahi 3A yaitu "Abang" (labia minor memerah), "Aboh" (vulva bengkak), "Anget" (suhu tubuh meningkat dan keluarnya lendir berwarna putih bening) dan manajemen pemeliharaan yang relatif sama. Bahan yang digunakan dalam penelitian ini adalah semen beku non sexing dan semen beku sexing dengan metode sedimentasi gradien densitas percoll (SGDP) yang diperoleh dari BBIB Singosari.

\section{Metode}

Metode yang digunakan dalam penelitian ini adalah percobaan lapang dengan sampel sebanyak 98 ekor sapi betina Persilangan Ongole, diantaranya 49 ekor di inseminasi dengan semen bekunon sexing dengan kualitas Post Thawing Motility (PTM) minimal 40\%, sedangkan 49 ekor lainnya diinseminasi menggunakan semen beku hasil sexing metode SGDPdengan spermatozoa berkromosom Y dan nilai PTM minimal $40 \%$.

Pelaksanaan IB dilakukan oleh inseminator di daerah setempat. Metode thawing dilakukan dengan menggunakan air kran dengan suhu $\pm 25^{\circ} \mathrm{C}$ selama 12 hingga 15 detik. Semen dideposisikan pada posisi 4+ yaitu pada posisi cornua uteri. Indikator kebuntingan berdasarkan pengamatan Non Return Rate (NRR) dan Conception Rate (CR). Data sekunder meliputi identitas peternak, tanggal IB, status marital ternak dan riwayat kesehatan ternak berdasarkan wawancara langsung dengan peternak. 
Variabel yang diamati untuk mengetahui keberhasilan inseminasi buatan dalam penelitian ini antara lain: Non Return Rate (NRR) dan Conception Rate (CR).

\section{Non Return Rate (NRR)}

Nilai NRR merupakan persentase sapi betina akseptor IB yang tidak kembali berahi selama 20-60 hari atau 60-90 harisetelahpelaksanaan IB (Susilawati, 2011). NRR yang digunakan dalam penelitian ini adalah $\mathrm{NRR}_{1}, \mathrm{NRR} 2$, dan $\mathrm{NRR}_{3}, \mathrm{NRR}_{1}$ diamati pada hari ke $18-21, \mathrm{NRR}_{2}$ diamati mulai hari ke 39-42, sedangkan $\mathrm{NRR}_{3}$ diamati pada hari ke43-60. Sapi yang menunjukkan tanda-tanda berahi setelah IB pertama maka dianggap gagal.

$\% \mathrm{NRR}=\frac{\text { Jumlah sapi di IB-jumlah sapi di IB ulang }}{\text { Jumlah sapi di IB }} X 100 \%$

\section{Conception Rate (CR)}

Nilai CR merupakan persentase akseptor IB yang mengalami kebuntingan pada IB pertama. Pada penelitian ini untuk memastikan keberhasilan kebuntingannya dengan mengamati fisik sapi pada kebuntingan lebih dari 8 bulan. Rumus CR menurut Susilawati (2011) dapat dihitung sebagai berikut :

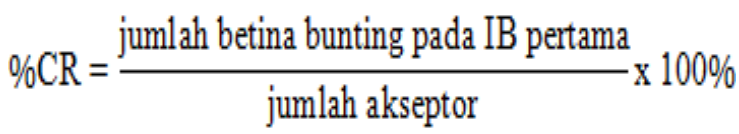

Data dari hasil penelitian yang diperoleh selanjutnya ditabulasi dan diolah secara deskriptif analisis dan membandingkan dengan literatur. Data dilanjutkan dengan uji proporsi satu pihak. Sudjana (2005) menyatakan bahwa rumus uji proporsi satu pihak sebagai berikut:

$$
z=\frac{\left(\frac{x_{1}}{n_{1}}\right)-\left(\frac{x_{2}}{n_{2}}\right)}{\sqrt{p q\left(\frac{1}{n_{1}}+\frac{1}{n_{2}}\right)}}
$$

\section{HASIL DAN PEMBAHASAN \\ Evaluasi keberhasilan IB berdasarkan Non Return Rate (NRR)}

Evaluasi keberhasilan IB dilakukan melalui pengamatan NRR. Susilawati (2013) menjelaskan bahwa NRR merupakan persentase sapi betina akseptor IB yang tidak kembali lagi berahi selama 2060 hari atau 60-90 hari pasca pelaksanaan IB. Data hasil pengamatan NRR dapat disajikan pada Tabel 1 .

Tabel 1. Hasil pengamatan $\mathrm{NRR}_{1}, \mathrm{NRR}_{2}$, dan $\mathrm{NRR}_{3}$

\begin{tabular}{lccccccc}
\hline \multirow{2}{*}{ Perlakuan } & & \multicolumn{2}{c}{$\mathrm{NRR}_{1}$} & \multicolumn{2}{c}{$\mathrm{NRR}_{2}$} & \multicolumn{2}{c}{$\mathrm{NRR}_{3}$} \\
\cline { 3 - 8 } & $\mathrm{n}$ & $\mathrm{n}$ & $\%$ & $\mathrm{~N}$ & $\%$ & $\mathrm{n}$ & $\%$ \\
\hline Semen Sexing (P1) & 49 & 43 & 87,76 & 36 & 73,47 & 33 & 67,35 \\
\hline Semen Non Sexing (P0) & 49 & 47 & 95,92 & 41 & 83,67 & 37 & 75,51 \\
\hline
\end{tabular}

Ket : NRR 1 merupakan persentase sapi yang tidak kembali birahi pada hari ke 18-21, $\mathrm{NRR}_{2}$ pada hari ke 39-42, sedangkan $\mathrm{NRR}_{3}$ pada hari ke 43-60

Hasil pengamatan NRR yang tersaji pada Tabel 1, dapat dijelaskan bahwa dari 98 ekor sapi yang diIB menunjukkan persentase NRR yang cukup baik. Dari setiap NRR pada IB menggunakan semen sexing terlihat bahwa persentase keberhasilannya lebih rendah dibandingkan dengan IB menggunakan semen non sexing.

Hasil pengamatan $\mathrm{NRR}_{1}, \mathrm{NRR}_{2}$, dan $\mathrm{NRR}_{3}$ yang tersaji pada Tabel 1, menunjukkan bahwa selalu terjadi penurunan nilai persentase NRR pada perlakuan IB 
menggunakan semen sexing dari $87,76 \%$ menjadi $73,47 \%$ dan $67,35 \%$, selanjutnya pada IB menggunakan semen non sexing dari $95,92 \%$ menjadi $83,67 \%$ dan $75,51 \%$. Penurunan tersebut diakibatkan karena terjadinya silent heat dan kematian embrio dini. Menurut pendapat Yekti dkk., (2017) dan Susilawati (2011) Silent Heat disebabkan oleh hipofungsi ovary, sedangkan kematian embryo disebabkan oleh keadaan endometrium yang tidak siap menerima blastosis mengakibatkan kegagalan implantasi. Penyebab yang lain adalah terjadinya kematian embrio dini, sehingga terjadi long cycle atau siklus estrus yang panjang.

\section{Evaluasi Keberhasilan IB berdasarkan Conception Rate (CR)}

Conception Rate merupakan persentase sapi betina bunting pada inseminasi pertama yang disebut juga sebagai angka kebuntingan. Angka kebuntingan pada penelitian ini ditentukan berdasarkan hasil pengamatan kebuntingan pada usia kebuntingan 8 bulan melalui pengamatan perubahan fisik tubuh ternak. Costa et al (2016) menjelaskan bahwa Conception rate adalah persentase sapi betina yang bunting pada aplikasi IB yang pertama dan digunakan sebagai indikator untuk mengukur tingkat kesuburan ternak. Hasil pengamatan CR pada sapi Persilangan Ongole dapat disajikan pada Tabel 2 .

Tabel 2. Hasil Pengamatan CR pada Sapi Persilangan Ongole yang di inseminasi menggunakan Semen Sexing dan Semen Non Sexing

\begin{tabular}{lccc}
\hline \multicolumn{1}{c}{ Perlakuan } & Jumlah akseptor (ekor) & Betina bunting (ekor) & CR (\%) \\
\hline Semen sexing & 49 & 27 & 55,10 \\
Semen non sexing & 49 & 32 & 65,31 \\
\hline
\end{tabular}

Ket: conception rate adalah persentase sapi betina yang bunting pada IB pertama

Berdasarkan Tabel 2 diketahui bahwa nilai CR pada IB menggunakan semen sexing lebih rendah yaitu sebesar $55,10 \%$ dibandingkan pada IB menggunakan semen non sexing yaitu sebesar $65,31 \%$. Hasil persentase CR pada IB menggunakan semen sexing belum mencapai nilai yang optimal karena berada dibawah nilai CR ideal yaitu $60 \%$. Nilai persentase CR dipengaruhi oleh beberapa faktor. Salah satu penyebab dari rendahnya nilai persentase CR pada perlakuan semen sexing dikarenakan sexing spermatozoa dihasilkan dengan proses yang panjang, sehingga mengakibatkan terjadinya penurunan kualitas spermatozoa. Hal ini sesuai dengan pernyataan Hayakawa (2012) menam- bahkan bahwa proses pemisahan kromosom dapat merusak kesuburan spermatozoa secara fisik/fisiologis, akibatnya kualitas spermatozoa jauh lebih rendah bila dibandingkan dengan spermatozoa yang dibekukan tanpa pemisahan kromosom ketika digunakan untuk IB atau fertilisasi in vitro (IVF).

Keberhasilan IB juga dipengaruhi oleh kondisi BCS yang menunjukkan tingkat kondisi lemak tubuh ternak. Menurut Budiawan dkk., (2015) menyatakan bahwa BCS digunakan untuk mengevaluasi manajemen pemberian pakan, menilai status kesehatan individu ternak dan membangun kondisi ternak pada waktu manajemen ternak yang rutin. BCS sapi Persilangan On- 
gole di lokasi penelitian dikelompokkan berdasarkan nilai BCS menggunakan skala 1-9, Sedangkan data di lapang yang ditemukan sapi betina rata-rata memiliki nilai BCS 2-5. Susilawati (2011) yang menyatakan bahwa BCS yang baik untuk bibit umumnya tergolong dalam kondisi sapi dengan berat badan sedang (4-6) dan memiliki fisiologi yang normal. Eversole $e t$ al (2009) menambahkan bahwa perbaikan pakan pada ternak hingga mencapai BCS sedang (5-7) memungkinkan sapi untuk mencapai kinerja reproduksi secara maksimum.

\section{KESIMPULAN}

Dapat disimpulkan bahwa nilai CR dan NRR pada sapi yang di IB dengan semen sexing lebih rendah dibandingkan dengan yang di IB menggunakan semen non sexing, namun semen sexing masih tetap dapat diaplikasikan untuk tujuan tertentu seperti mendapatkan anak sesuai dengan harapan.

\section{UCAPAN TERIMAKASIH}

Ucapan Terimakasih Kepada Bank Indonesia Surabaya yang telah memfasilitasi pendanaan dan peternak sapi PO di Kabupaten Malang sebagai Resipien pada penelitian ini.

\section{DAFTAR PUSTAKA}

Budiawan, A., M. N. Ihsan, dan S. Wahjuningsih. 2015. Hubungan body condition score terhadap service per conception dan calving interval Sapi potong Peranakan Ongole di Kecamatan Babat Kabupaten Lamongan. J. Ternak Tropika, 16(1): 34-40.

Boro, P., B. C. Naha, A. Madkar, and C. Prakash. 2016. Sexing of semen in bulls; A Mini Review. International Journal of Applied Research, 2(4): 460-462.

Costa, N. D., T. Susilawati, N. Isnaini, and M. N. Ihsan. 2016. The difference of artificial insemination succesful rate of ongole filial cattle using cold semen with different storage time with tris aminomethane egg yolk dilution agent. IOSR Journal Of Pharmacy, 6(6): 13-19.

Eversole, D. E., M. F. Browne, J. B. Hall, and R. E.Dietz. 2009. Body Conditioning Scoring Beef Cows. Virginia State University : Virginia Cooperative Extension.

Hayakawa, H. 2012. Sperm sexing in the cattle industry. Journal of Mammalian Ova Research, 29(3): 199-123.

Kusumawati,E.D, N. Isnaini, A.P.A Yekti, M. Luthfi, 1. affandhy, G. pamungkas, Kuswati, A. Ridhowi. H. Sudarwati, T. susilawati, S. Rahayu, 2017. The quality of sexed semen on filial ongole bull using percoll density gradient centrifugation method. Asian Jr. of Microbiol, 19(1) : 189-199.

Prakash, M. A., A. Kumaresan, A. Manimaran, R. K. Joshi, S. S. Layek, T. K. Mohanty, and R. R. Divisha. 2014. Sexing of spermatozoa in farm animals; a Mini Review. Advances in Animal and Veterinary Sciences, 2(4): 226-232.

Sudjana. 2005. Metoda Statistika. Bandung: Tarsito.

Susilawati, T. 2011. Tingkat keberhasilan inseminasi buatan dengan kualitas dan deposisi semen yang berbeda pada Sapi Peranakan Ongole. 
Jurnal Ternak Tropika. 12(2): 1524.

Susilawati, T. 2013. Pedoman Inseminasi Buatan Pada Ternak. Malang: Universitas Brawijaya (UB) Press.

Susilawati, T. 2014. Sexing Spermatozoa. Malang: Universitas Brawijaya (UB) Press.

Yekti, A.P.A., T. Susilawati, M.N. Ihsan, dan S. Wahjuningsih. 2017. Fisiologi Reproduksi Ternak (Dasar Manajemen Reproduksi). Malang: Universitas Brawijaya (UB) Press. 